\title{
Withdrawing Payment for Nonscientific Drug Therapy
}

\section{Citation}

Soumerai, Stephen B. 1990. “Withdrawing Payment for Nonscientific Drug Therapy." JAMA 263 (6) (February 9): 831. doi:10.1001/jama.1990.03440060077036.

\section{Published Version}

doi:10.1001/jama.1990.03440060077036

\section{Permanent link}

http://nrs.harvard.edu/urn-3:HUL.InstRepos:32692594

\section{Terms of Use}

This article was downloaded from Harvard University's DASH repository, and is made available under the terms and conditions applicable to Other Posted Material, as set forth at http:// nrs.harvard.edu/urn-3:HUL.InstRepos:dash.current.terms-of-use\#LAA

\section{Share Your Story}

The Harvard community has made this article openly available.

Please share how this access benefits you. Submit a story.

Accessibility 


\title{
Withdrawing Payment for Nonscientific Drug Therapy
}

\section{Intended and Unexpected Effects of a Large-Scale Natural Experiment}

\author{
Stephen B. Soumerai, ScD; Dennis Ross-Degnan, ScD; Steven Gortmaker, PhD; Jerry Avorn, MD
}

\begin{abstract}
Little is known about the effect on clinical decision making of nonreimbursement for ineffective medical technologies. Using a time-series design, we studied the effects of cessation of government payment for 12 categories of drugs of questionable efficacy (Drug Efficacy Study Implementation drugs) in a random sample of the New Jersey Medicaid population ( $\mathrm{N}=390465)$ and in four cohorts of regular users of these products. We measured changes in the overall levels of prescriptions, expenditures, and physicians' use of substitute drugs. Although withdrawn drugs accounted for $7 \%$ of prescriptions in the base year, there was no measurable reduction in overall drug use or expenditures after the regulation; prescription rates actually rose from 0.86 to 1.00 monthly prescriptions per enrollee throughout the 42-month study. Controlling for preexisting trends, an estimated drop in the use of study drugs of 21.7 prescriptions per 1000 enrollees per month was offset by an increase in the use of substitute drugs of 33.7 prescriptions. Both desirable and unimproved therapeutic substitutions were observed. Used alone, curtailment of reimbursement for marginally effective therapies results in both desirable and unintended clinical substitutions and may not reduce costs. Supplementing such restrictions with education may be necessary to promote practices that are more therapeutically and economically appropriate.
\end{abstract}

(JAMA. 1990;263:831-839)

PRESSURES continue to mount to contain costs by restricting the therapeutic options of physicians. One increasingly popular but poorly studied strategy for raising the cost-effective-

\footnotetext{
From the Department of Social Medicine, the Program for the Analysis of Clinical Strategies, Harvard Medical School, and the Beth Israel Hospital, Boston Mass (Drs Soumerai, Ross-Degnan, and Avorn); and Mass (Ors Soumerai, Ross-Degnan, and Avorn); and
the Department of Behavioral Sciences, Harvard School of Public Health, Boston (Dr Gortmaker).

Reprint requests to Department of Social Medicine Harvard Medical School, 643 Huntington Ave, Boston, MA 02115 (Dr Soumerai)
}

ness of clinical decisions is for government and private payers of health care to eliminate reimbursement for "marginally effective" or "irrational" health care technologies and services. Defining marginal therapies is difficult both technically and politically, and the danger exists that some restrictions on physicians' choices may harm patients. ${ }^{1,2}$

In the Medicaid program, one common short-range, cost-control strategy has been to eliminate coverage of certain services, including some drugs. ${ }^{3} \mathrm{~A}$ number of European and developing nations have also restricted public financing for specific classes of nonessential medications. ${ }^{4,5}$ Despite the widespread occurrence of these reimbursement policies, their consequences and the magnitude of their savings and costs are not well understood, particularly in the office-practice setting, where most clinical decisions occur without ongoing monitoring. ${ }^{6}$ This report presents the results of a natural experiment in which a large number of prescription drugs that were judged to be ineffective or irrational were suddenly eliminated from reimbursement through Medicaid and other public programs. Outcomes were measured using a patient-level prescription claims database that covered a sample of 390465 individual patients in the New Jersey Medicaid program during a 42-month period.

Prescription-drug use provides a good model for research regarding the impact of payment-restriction policies. Drug prescribing is one of the most common and important clinical decisions in medical practice; approximately $75 \%$ of all visits to the physician end with one or more drug prescriptions ${ }^{7}$; total nationwide expenditures for prescription drugs were approximately $\$ 33$ billion in $1987 .^{8}$ Although this represents a relatively small proportion of national health care expenditures, the overall clinical and economic impact of appropriate and inappropriate drug use is substantially higher. ${ }^{910}$ 


\section{BRIEF HISTORY OF THE DRUG EFFICACY STUDY IMPLEMENTATION (DESI) PROCESS}

The 1962 Kefauver-Harris amendments to the Food and Drug Act required that drug manufacturers provide evidence of efficacy as well as safety before marketing. ${ }^{11}$ The amendments also stipulated that all drugs approved before 1962 (or DESI drugs) be reviewed for determinations of efficacy as a condition for continued marketing. The formidable task of retrospective review was initially given to the National Academy of Sciences/National Research Council, which convened 200 medical and scientific specialists between 1966 and 1969 to evaluate the efficacy of 3925 DESI drugs for more than 16000 indications. ${ }^{12}$ During the next 3 years, scientists at the Food and Drug Administration reviewed these reports and determined that $40 \%$ of DESI drugs lacked the requisite evidence. Many of these products either had no evidence of efficacy (eg, peripheral or cerebral vasodilators for senile dementia) or represented irrational fixed-ratio combinations of several therapeutic agents (eg, analgesics or bronchodilators combined with barbiturates), which the National Academy of Sciences/National Research Council panels judged to pose unnecessary risks without added efficacy. During the 1970 s and early $1980 \mathrm{~s}$, various scientific, legal, and marketing maneuvers were undertaken by some pharmaceutical companies to impede the withdrawal of specific agents, while public interest groups attempted to expedite the withdrawal of many irrational agents from the marketplace. Following a suit filed by the Health Research Group and the National Council of Senior Citizens that sought a cutoff of all Medicare, Medicaid, and other public reimbursement for "less-than-effective" drugs, in late 1981 the administrator of the Health Care Financing Administration sent telegrams to all state Medicaid administrators that ordered them to cease reimbursement for 141 ineffective DESI drugs and similar products. Most states stopped payment for these drugs by March 1982. However, many DESI drugs continued to be available for sale because of lengthy legal and administrative processes necessary to force their withdrawal from the market.

\section{MEASURING IMPACTS OF THE DESI PROGRAM}

Because of the demonstrated lack of effectiveness of many of these agents, some Food and Drug Administration officials predicted that their abandon- ment nationwide would "have a major impact on the quality of the medicines they [patients] take"13; yet, no largescale and generalizable research has been conducted on the impact of such restrictions on physicians decisions. One case study observed substitution effects after selected DESI withdrawals. ${ }^{14}$ However, the sample for each drug group was too small (fewer than five patients), and the 3-month preintervention period too brief to reliably control for several key variables, such as preexisting trends in the prescribing of substitute medications, the frequency of withdrawal of these drugs in the absence of the policy, and other confounding factors such as changes in eligibility. Two other studies of the effects of eliminating payment for nonnarcotic analge$\operatorname{sics}^{15}$ and nonreimbursement for antacids, cough and cold preparations, and antihistamines ${ }^{16}$ suffered from similar methodological limitations. Since newer drugs are likely to be increasing in use at the same time that older drugs may be declining, even in the absence of restrictions on older drugs, failure to control for preintervention trends would inflate their estimates of substitution effects. Although randomized, controlled trials are impossible in studies of region-wide policy changes, careful collection and analysis of observations of large numbers of patients for several years before and after initiation of the intervention can substantially improve both the validity and precision of estimated effects. ${ }^{17}$

This investigation was designed to extend and improve on previous studies in several ways. We used a large sample of 390465 Medicaid patients to achieve stable estimates of drug use and studied 12 broad categories of DESI drugs, 66 potential substitutes, and 3 comparison drug categories to achieve greater validity and generalizability of the findings. Preexisting trends were controlled for in all analyses and all substitute categories were defined in advance to reduce bias. Identifying large preintervention cohorts of DESI drug users made it possible to achieve maximum power and control for other confounders. The analysis attempted to answer the following questions: Did the reimbursement restrictions on DESI drugs reduce overall drug use and costs in the Medicaid system? What was the nature of substitute prescribing? Did specific substitution effects represent clear improvements in therapy relative to nonreimbursed drugs? Were patients who were taking combination drugs switched to effective single-agent therapies? What were the relative costs of withdrawn products vs their identified substitutes? These findings may make it possible to understand both the opportunities and limits of restricting physicians' choices through regulated reimbursement.

\section{METHODS}

\section{Study Populations and Data Sources}

The population studied included all persons who were eligible for the New Jersey Medicaid program during the period from July 1980 to December 1983. A $40 \%$ random sample of recipients who were enrolled during this period was selected, yielding a study population of 390465 individuals. Many members of this study population were not enrolled in Medicaid continuously throughout the study period because of fluctuations in income, family status, or other eligibility criteria. To calculate rates of pharmaceutical use correctly, the monthly eligibility status and demographic characteristics of all Medicaid recipients were ascertained; the actual eligible population during each study month was then calculated. To investigate whether possible secular changes in the composition of the study population could be responsible for some of the observed changes in pharmaceutical use, we examined trends in the distribution of age, sex, and race in New Jersey Medicaid. To further control for changes in eligibility, we also observed four cohorts of regular users of particular DESI drugs (see later herein).

We analyzed data regarding all prescriptions actually filled and reimbursed by Medicaid in the study population during the 42-month study (17 months before and 25 months after the change in reimbursement policy). These data included the recipient identifier, the drug product code of the medication, the number of units dispensed, and the date the prescription was filled. Our own work and that of others using drug claims data from Medicaid programs have found them to be highly reliable and complete. , $^{21-23}$

\section{Selection and Classification of Study Drugs}

A panel of six clinicians including internists, geriatricians, and pharmacists was convened to select DESI drugs that were suitable for study, to review the indications for which they were used, and to define all plausible substitute therapies and their relative efficacy for specific indications. The panel members were provided with appropriate reference material throughout this process, including the National Academy of Sciences/National Research Council report ${ }^{12}$ and other background informa- 
tion regarding DESI drugs and sections of the American Medical Association's Drug Evaluations ${ }^{24}$ for both DESI drugs and plausible substitute therapies. The selection and evaluation process was carried out first by questionnaires completed independently, followed by five group sessions to build consensus about the specific drug substitutions. To avoid bias, the entire process was completed before the results of data analysis were known.

The DESI drugs were initially selected for study according to the following criteria: (1) the drug group should be widely prescribed before the policy, (2) the drug should have relatively specific indications, (3) if possible, there should exist other therapies of varying efficacy for these indications. Using these criteria, 12 DESI drug categories were chosen, which represented a broad range of both acute and chronic health problems: peripheral or cerebral vasodilators, asthma and sedative combinations, gastrointestinal antispasmodies with sedatives, analgesic combinations (antimigraines), combination steroid-antibiotic creams and ointments, ineffective antiemetics (trimethobenzamide), analgesic and sedative combinations, phenylbutazone-antacid combinations, nitrate and meprobamate combinations, diuretic and potassium combinations, cerebral stimulants, and antibiotic combinations.

Several drug compendiums ${ }^{25-27}$ were used to identify all marketed products chemically equivalent to the DESI drugs chosen and all the defined substitutes for each category. The panel also evaluated each substitute relative to the DESI drug it replaced in terms of its potential for improving therapy as (1) likely, (2) uncertain, or (3) unlikely. These ratings were based on both efficacy and safety. In addition to rating therapeutic improvement, panel members also estimated the proportion of use of each DESI group by indication that each substitute would likely replace. Of course, not all substitutions for the DESI products studied will necessarily be identified by our procedures because of the use of DESI drugs for indications other than the ones defined or substitution of other drugs. Thus, our estimates of substitution effects are conservative.

\section{DESI-USER COHORTS}

Certain DESI drugs had marketed indications for treatment of chronic conditions (eg, peripheral or cerebral vasodilators and bronchodilator plus sedative combinations). Identifying cohorts of regular users of these medications allowed patient-level specificity in the identification of substitutes and greater control for changes in the composition of the overall study group. To minimize regression toward the mean, the "long-term users" were required to have filled at least one prescription during each4-month period for at least 16 months before the DESI withdrawal policy.

Time-series of drug use were constructed by aggregating by month all prescriptions for each category of DESI drug group, substitute medications, and comparison drugs in the full sample population, as well as in each group of DESI drug users. Four of the 12 DESI categories were not prescribed with enough frequency to allow reliable estimates of change (nitrate and meprobamate combinations, diuretic and potassium combinations, cerebral stimulants, and antibiotic combinations), so these drugs and their substitutes were not analyzed individually, but were included in group totals. Dollar values were calculated by assigning to each prescription the allowable perunit cost from the New Jersey formulary, plus the dispensing fee. All series were converted to rates by dividing each month's total by the number of persons enrolled in that cohort for that month. The resulting time-series were analyzed by specifying a segmented linear regression model with correction for serially autocorrelated observations. ${ }^{28}$ This class of models is described in standard econometrics textbooks, ${ }^{29}$ and its applicability to health problems has been demonstrated. ${ }^{2,30,31}$

The basic model included terms to estimate the following variables: preexisting prescribing level for each drug group in the first month of the observation period (intercept), trend in prescribing before implementation of the DESI policy, change in level of prescribing attributable to the policy, and change in prescribing trend after the policy. Not all patients fill a prescription each month, so after withdrawal of the DESI products there was generally a brief transition period of 2 to 3 months until patients were placed on a new regimen (Figs 1 and 2). For this reason, the month in which the policy was implemented and the following 2 months were excluded from the statistical models but are included in all figures.

To derive conservative estimates of the impact of the withdrawal on substitute drug use, we interpreted only sudden and significant discontinuities in the levels of the time-series as likely to be true effects of the intervention. The two terms for trend before and after the policy were always included as covariates in the models to ensure that more modest changes following the DESI withdrawal, which could have been caused by many other gradually changing historical factors (eg, marketing patterns), were not included as principal effects of the intervention.

Many drugs exhibit marked seasonal variations in use because of cyclic fluctuations in the illnesses for which they are prescribed. Therefore, for every timeseries, an alternative to the basic model was tested that included quarterly seasonal adjustment terms. The seasonal terms were included in the final model only if they were statistically significant. This ensures the most reliable estimate of the impact of the policy, controlling for seasonality. Because we hypothesized that the withdrawal would result in substantial increases in the level of prescribing of substitute drugs, if it had an impact at all, significance tests and confidence intervals were based on one-sided critical values.

\section{RESULTS \\ Background Characteristics of the Study Population}

The background characteristics of the total enrolled study population ( $\mathrm{N}=390465$ patients) were extremely stable during the 42-month observation period. Throughout the study, women constituted an average of $65 \%$ of the population, with almost no monthto-month variation $(\mathrm{SD}<0.01 \%)$. Thirty-eight percent of recipients were white $(\mathrm{SD}=0.9 \%), 41 \%$ were black $(\mathrm{SD}=0.5 \%$ ), and $21 \%$ were members of another race $(\mathrm{SD}=1.2 \%)$. Children (aged $<20$ years) represented $51 \%$ $(\mathrm{SD}=1.5 \%)$ of enrollees, those between ages 21 and 60 years accounted for $35 \%$ $(\mathrm{SD}=1.5 \%)$, and $15 \%$ were older than 60 years $(\mathrm{SD}=0.3 \%)$. Analyses of a population comprising only recipients who were continuously enrolled in Medicaid during all 42 months produced almost identical results; therefore, the results presented herein for changes in total drug use are drawn from the entire $40 \%$ random sample.

\section{Effects on Total Prescriptions in Medicaid}

Monthly rates of prescriptions filled per Medicaid enrollee are presented in Fig 1 for all drugs, DESI drugs, and all defined substitutes. The DESI drugs represented $7 \%$ of all prescriptions for this group in the base year and were acquired at a rate of 60.4 prescriptions per 1000 enrollees per month; study DESI drugs accounted for approximately $40 \%$ of all DESI drugs in that year and were characterized by a more stable preintervention trend (Fig 1, top). As expected, study DESI pre- 

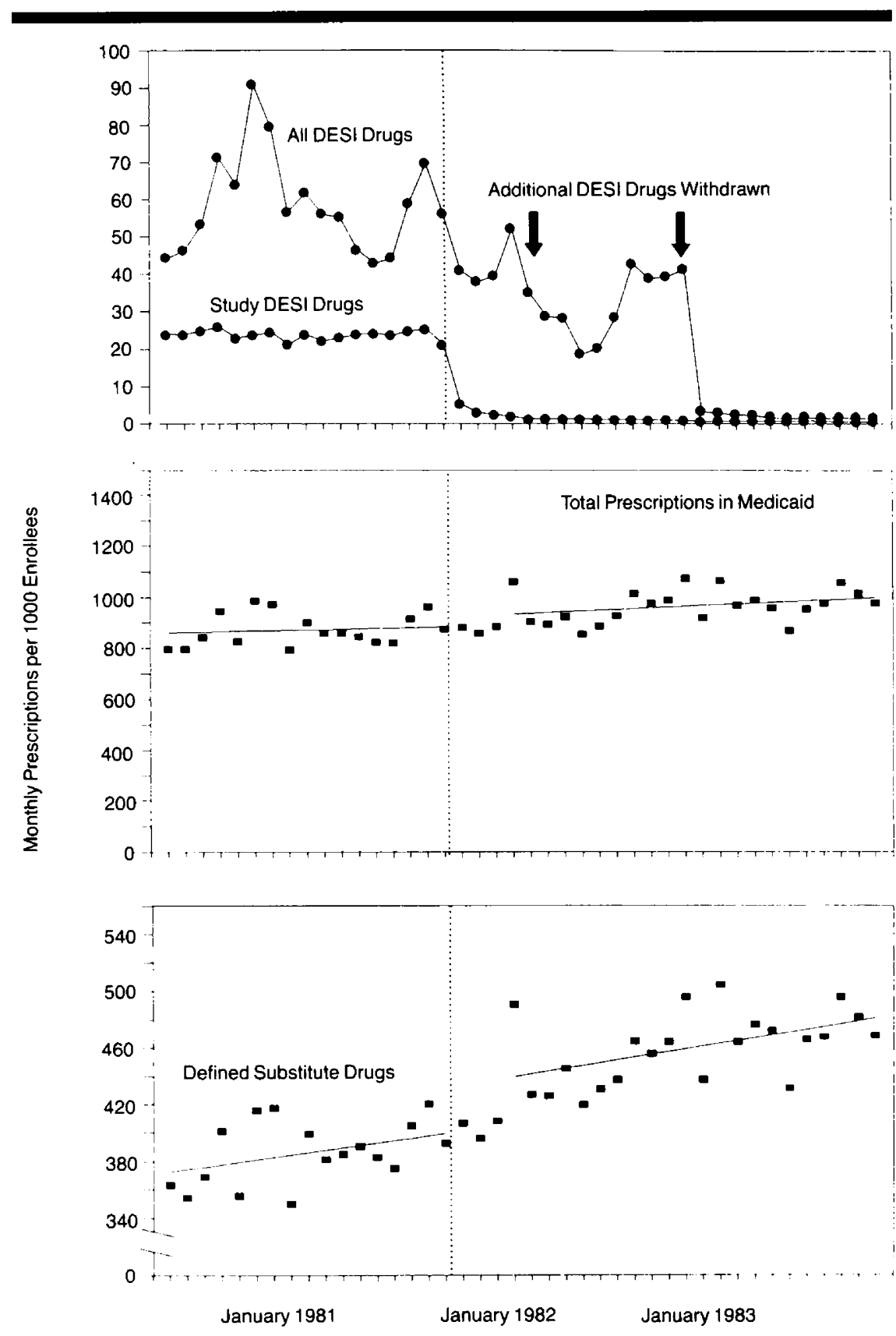

Fig 1. - Time-series of monthly prescriptions per 1000 enrollees for all Drug Efficacy Study Implementation (DESI) drugs and study DESI drugs (top), all drugs in Medicaid (center), and defined substitutes (bottom). Segmented regression lines were fit to the preintervention and postintervention data as described in the text. Dotted line represents the time of the withdrawal of the DESI drugs studied.

scriptions dropped to almost zero immediately following the intervention; most of the remaining DESI drugs were withdrawn in January 1983.

Despite the sharp drops in the number of DESI prescriptions filled, overall drug use rates actually rose modestly throughout the observation period, from approximately 860 monthly prescriptions per 1000 enrollees to 998 prescriptions by the end of the 42 -month drugs in January 1983. The likelihood that a modest proportion of recipients continued to pay for DESI drugs out-ofpocket $^{14}$ further supports the hypothesis that total drug use did not decline and may even have risen slightly.

The bottom graph in Fig 1 suggests a possible explanation for this lack of change in overall drug use. Following the DESI drug withdrawal, there was a sudden increase in level of use of substitute drugs of 33.7 prescriptions per 1000 enrollees per month $(P=.002)$. The $90 \%$ confidence intervals for the previously mentioned estimates of changes in the levels of drug use are -22.8 to -20.7 for study DESI drugs and +15.5 to +51.9 for all defined substitutes.

Other Medicaid-wide drug policy changes could not have accounted for these effects. The time-series for all three control groups (insulin, digoxin, and anti-infective ophthalmic ointments), which represent neither DESI drugs nor plausible substitute therapies, were extremely stable over time; no increases in levels of use occurred for any of these products following the restriction policy.

\section{Therapeutic Substitution Among DESI Drug Users}

We next analyzed which medications were chosen to replace specific DESI drugs and their relative therapeutic efficacy in four DESI drug user cohorts. Significant increases occurred in 10 substitute categories: 2 of these represented probable improvements in therapy, 3 substitutions were indeterminate, and 5 represented unlikely improvements in therapy. Unless otherwise stated, all level-change estimates are in prescriptions per 100 patients per month. All effects presented were significant at the $P=.05$ level and, in many cases, $P<.0001$.

Patients Who Took Peripheral or Cerebral Vasodilators. - The largest group of users of a single DESI drug group comprised patients $(n=468)$ who received long-term treatment with peripheral or cerebral "vasodilators" such as cyclandelate (eg, Cyclospasmol) or nylidrin (eg, Arlidin). The large majority of this population were older than 60 years $(90 \%)$ and women $(76 \%)$. Overall, $69 \%$ of recipients of vasodilators did not receive any ineffective substitute drugs through Medicaid after the policy change. However, large increases in use were found for two drugs (Fig 2 and Table 1), neither of which was likely to represent a meaningful improvement in therapy: papaverine $(+15.7$ prescriptions $[+282 \%]$, another equally ineffective vasodilator that had escaped DESI withdrawal because it had been 


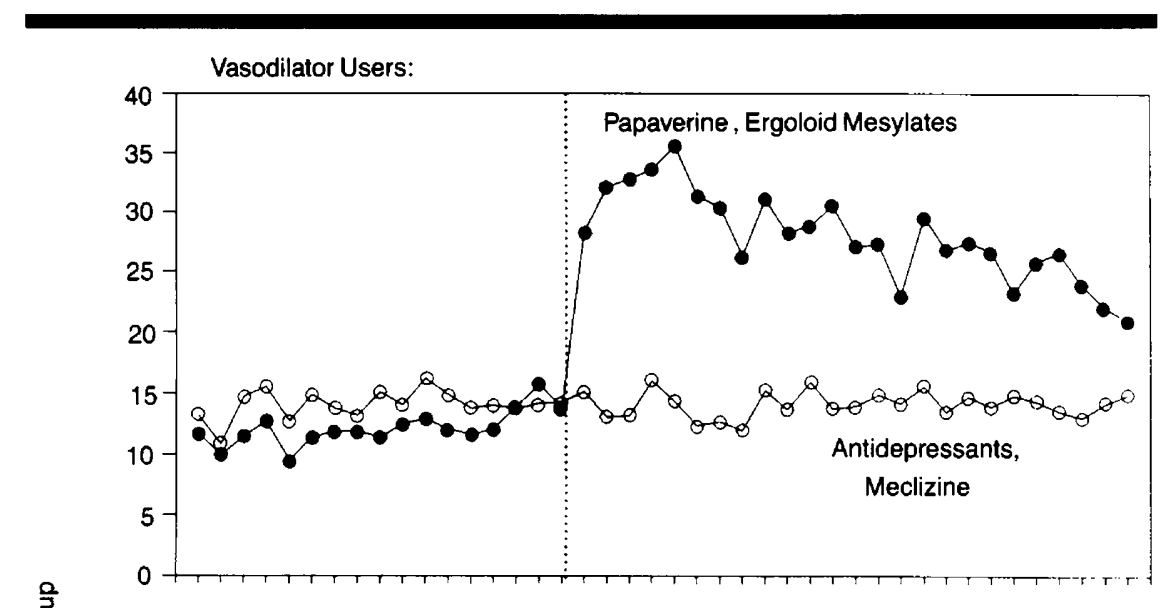

tients per month $(+67 \%$, Table 1$)$; this use rate continued to rise slightly throughout the observation period. Conversely, although it was hypothesized that physicians might prescribe single-agent barbiturates or other sedatives (eg, benzodiazepines) in an attempt to reconstitute the irrational combination of therapies, this effect did not occur, except for a modest increase in the use of hydroxyzine (Atarax, Vistaril) in the treatment of these patients. The data indicate that most, but not all, patients with asthma and chronic obstructive pulmonary disease continued to receive an effective respiratory agent.

Patients Who Took Antispasmodic Agents That Contained Sedatives. This category contained primarily anticholinergic agents combined with phenobarbital (eg, Donnatal Extentabs) or with chlordiazepoxide (eg, Librax). Two-hundred forty-nine patients in the sample were long-term users, $88 \%$ were women. The largest absolute substitution effect was for single-agent benzodiazepine tranquilizers (Fig 2 and Table 1). Use of other belladonna-type preparations increased by $113 \%$ from the expected level of 5.7 prescriptions per month. Some barbiturate-anticholinergic combinations remained available, but physicians did not increase their prescribing of these agents.

Patients Who Took Combination Analgesics. -This group contained various combination analgesics with or without sedatives, often prescribed for migraine (eg, Migral). Only 38 regular users of these drugs could be identified in the $40 \%$ sample. Although effective alternative therapies existed at the time of the study, the largest increases occurred for other combination analgesic products that contained constituents that were abusable and of modest efficacy, such as propoxyphene, pentazocine, and barbiturates (Table 1). These substitute drugs increased in level from an estimated 23.1 prescriptions per $100 \mathrm{pa}$ tients per month before the DESI restriction to 41.5 prescriptions afterward, an increase of $80 \%$. The next largest increase was seen for codeinecontaining preparations; smaller increases also occurred for nonsteroidal anti-inflammatory agents, including phenylbutazone.

\section{Substitution Effects for Drugs Used to Treat Acute Conditions}

Substitutions for DESI drugs intended for acute medical problems were estimated in the entire $40 \%$ sample. Unless otherwise stated, all levels and effects herein are in prescriptions per $1000 \mathrm{en}$ rollees per month; all effects are signifi- 


\begin{tabular}{|c|c|c|c|c|}
\hline DESI Category & $\begin{array}{c}\text { Substitute Drug } \\
\text { (Average Clinical Rating Across } \\
\text { All Indications) } f\end{array}$ & $\begin{array}{c}\text { Expected } \\
\text { Prescriptions per } \\
100 \text { Patients } \\
\text { per Month } ¥ \\
\end{array}$ & $\begin{array}{l}\text { DESI Level\$ } \\
\text { Change (SE) }\end{array}$ & $\begin{array}{c}\text { \% Change: } \\
\text { From Expected } \\
\text { Level }\end{array}$ \\
\hline \multirow{5}{*}{$\begin{array}{l}\text { Peripheral/cerebral vasodilators } \\
(n=468)\end{array}$} & Antidepressants (2) & 10.3 & $-0.7(0.57)$ & $\ldots$ \\
\hline & Meclizine (2) & 4.0 & $-1.0(0.63)$ & $\ldots$ \\
\hline & B vitamins (3) & 3.5 & $-0.4(0.56)$ & $\ldots$ \\
\hline & Ergoloid mesylates (3) & 4.8 & $+3.4(0.53) \pi$ & 70 \\
\hline & Papaverine (3) & 5.6 & $+15.7(0.76) \uparrow$ & 282 \\
\hline \multirow{7}{*}{$\begin{array}{l}\text { Asthma/sedative combinations } \\
(n=173)\end{array}$} & Aminophylline/theophylline (1) & 34.4 & $+23.1(4.65) \uparrow$ & 67 \\
\hline & Sympathomimetics (1) & 64.4 & $-5.7(5.24)$ & $\ldots$ \\
\hline & Steroid inhalers (1) & 2.9 & $-1.3(1.04)$ & $\ldots$ \\
\hline & Barbiturates (3) & 2.4 & $-0.5(0.64)$ & $\ldots$ \\
\hline & Benzodiazepines (3) & 29.4 & $-2.4(2.18)$ & $\ldots$ \\
\hline & Hydroxyzine (3) & 2.4 & $+2.6(0.9) \#$ & 110 \\
\hline & Oral steroids (3) & 14.8 & $+0.1(2.37)$ & $\ldots$ \\
\hline \multirow{6}{*}{$\begin{array}{l}\text { Gastrointestinal antispasmodics } \\
\text { with sedatives }(n=249)\end{array}$} & Fiber/binders (1) & 2.9 & $-1.1(0.58)$ & $\ldots$ \\
\hline & Antacids (2) & 21.3 & $+1.0(2.01)$ & $\ldots$ \\
\hline & Belladonna alkaloids (2) & 5.7 & $+6.4(1.02) 9$ & 113 \\
\hline & Benzodiazepines (2) & 32.4 & $+9.9(2.47) \#$ & 31 \\
\hline & Opiate/morphine analogues (2) & 6.2 & $+1.2(1.13)$ & $\ldots$ \\
\hline & Barbiturates (3) & 2.6 & $+0.1(0.51)$ & $\ldots$ \\
\hline \multirow[t]{6}{*}{ Analgesic combinations $(n=38)$} & Amitriptyine/imipramine (1) & 4.5 & $-2.3(4.46)$ & $\ldots$ \\
\hline & Aspirin/acetaminophen (1) & 5.1 & $-1.7(1.6)$ & $\ldots$ \\
\hline & $\begin{array}{l}\text { Nonsteroidal anti-inflammatory drugs (except } \\
\text { phenylbutazone) (1) }\end{array}$ & 0 & $+3.4(1.55)^{* *}$ & $\ldots t t$ \\
\hline & Codeine/opiate-containing agents (2) & 12.1 & $+14.0(6.52)^{* *}$ & 116 \\
\hline & Low-efficacy agents with abuse potential (3) $\ddagger \ddagger$ & 23.1 & $+18.4(8.93)^{* *}$ & 80 \\
\hline & Phenylbutazone (3) & 0 & $+4.6(0.97)$ & $\ldots \dagger \dagger$ \\
\hline
\end{tabular}

*Categories with fewer than two expected or observed prescriptions per 100 users per month were eliminated from the table.

$t 1$ indicates likely improvement in therapy; 2 , uncertain effect; and 3 , improvement unlikely.

tEstimated level at start of postintervention period, based on preintervention trend.

§Estimated change in level of monthly series (prescriptions per 100 patients per month).

$\|$ Percent change presented only for significant effects $(P<.05)$.

$\llbracket P<.0001$.

$\# P<.01$

$* * P<.05$

††For models in which the expected use after DESI restriction was 0 or less, no percent change was computed.

\#łncludes analgesic combinations containing pentazocine, propoxyphene, or barbiturates.

cant at the $P=.05$ level and, generally, $P<.01$. Combination steroid and antibiotic creams were one of the most popular DESI product categories before restriction, and they were being prescribed at a rate of 8.8 prescriptions per 1000 enrollees per month at the time of the withdrawal. The largest substitution effect was observed for singleagent steroid creams $(+3.7$ prescriptions $[+17 \%]$, preferable in most cases over the combination. Use of antibiotic creams without steroids also increased $23 \%$, by 1.4 prescriptions, although the appropriateness of this therapy in most clinical situations is doubtful.

Several substitution effects occurred in response to the withdrawal of the antiemetic trimethobenzamide (Tigan) (Table 2). Use of prochlorperazine, probably an improvement in therapy, increased by $34 \%$; use of metoclopramide and promethazine also increased by $162 \%$ and $30 \%$, respectively.

The analgesic and sedative combinations and phenylbutazone and antacid combinations that were withdrawn were judged to have similar substitute therapies and were, therefore, analyzed together (Table 2). Following the cessation of reimbursement for these drugs, the largest absolute increase in prescription use occurred for the nonsteroidal anti-inflammatory drugs $(+2.1$ prescriptions $[+5.7 \%])$, even after controlling for a rising preintervention trend. However, significant substitution effects occurred for less-desirable substitute therapies such as analgesic combinations that contained pentazocine or propoxyphene $(+0.4$ prescriptions $[+5.9 \%])$. The most common response to the ending of reimbursement for a combination of phenylbutazone and a small dose of antacid (Butazolidin Alka) was for physicians to prescribe phenylbutazone alone, although it was probably the least desirable nonsteroidal anti-inflammatory drug available at the time (Table 2). ${ }^{24(1067)}$ No increases were observed for the other seven categories of analgesics that were followed up (Table 2).

Many of the DESI combination products promoted as analgesics or antispasmodic agents contained abusable seda- tives such as a barbiturate or meprobamate. ${ }^{24(p 96-99)}$ As a result, it is not surprising that the use of some psychoactive drugs (Table 2) increased following the intervention. The most prevalent substitution effect in these patients was for the benzodiazepines $(+3.9$ prescriptions $[+10 \%])$. However, there was also an increase in the level of use of single-agent barbiturates $(+0.7$ prescriptions $[+8.6 \%]$ ), which occurred after a prior downward trend in their use. $^{24(p 96-99)}$

\section{Changes in Medicaid \\ Drug Expenditures}

Based on constant (1986) drug prices, the estimated New Jersey Medicaid expenditure for all DESI drugs during the base year was $\$ 4.5$ million. No decrease in drug expenditures was found following removal of DESI drugs from the Medicaid formulary. In fact, taking into account preexisting trends, the best estimate of the change that occurred with the DESI intervention in total Medicaid drug expenses per 1000 enrollees was a $3.2 \%$ increase of $\$ 394$ per month, al- 


\begin{tabular}{|c|c|c|c|c|}
\hline Category & Substitute Drug (Clinical Rating)† & $\begin{array}{c}\text { Expected } \\
\text { Prescriptions per } \\
1000 \text { Patients } \\
\text { per Month } \ddagger\end{array}$ & $\begin{array}{l}\text { DESI Level\$ } \\
\text { Change (SE) }\end{array}$ & $\begin{array}{c}\% \text { Change } \| \\
\text { From Expected } \\
\text { Level }\end{array}$ \\
\hline \multirow{5}{*}{$\begin{array}{l}\text { Steroid/antibiotic creams and } \\
\text { ointments }\end{array}$} & Steroid creams (1) & 22.4 & $+3.7(1.36) \#$ & 16.6 \\
\hline & Clotrimazole (2) & 2.6 & $+0.6(0.25) \#$ & 24.9 \\
\hline & Hydroxyzine (2) & 6.5 & $+0.1(0.27)$ & $\ldots$ \\
\hline & Oral diphenhydramine (2) & 7.9 & $+0.4(0.71)$ & $\ldots$ \\
\hline & Antibiotic creams (3) & 6.1 & $+1.4(0.69)^{* *}$ & 22.7 \\
\hline \multirow[t]{4}{*}{ Antiemetics } & Prochlorperazine (1) & 1.3 & $+0.4(0.11) \#$ & 33.5 \\
\hline & Meclizine (2) & 2.9 & $+0.0(0.11)$ & $\ldots$ \\
\hline & Metoclopramide (2) & 0.2 & $+0.4(0.04) 9$ & 162.1 \\
\hline & Promethazine (2) & 1.3 & $+0.4(0.13) \#$ & 29.7 \\
\hline \multirow{10}{*}{$\begin{array}{l}\text { Analgesic/sedative } \\
\text { combinations; } \\
\text { phenylbutazone/antacid; } \\
\text { antimigraines }\end{array}$} & $\begin{array}{l}\text { Nonsteroidal anti-inflammatory drugs (except } \\
\text { phenylbutazone) (1) }\end{array}$ & 37.2 & $+2.1(1.25)^{* *}$ & 5.7 \\
\hline & Aspirin/acetaminophen (1) & 13.6 & $+2.0(1.29)$ & $\ldots$ \\
\hline & Antacids (2) & 10.2 & $+0.2(0.36)$ & $\ldots$ \\
\hline & Codeine-containing agents (2) & 11.1 & $+0.7(0.54)$ & $\ldots$ \\
\hline & Analgesic combinations with abuse potential (3) $\mathrm{t \dagger}$ & 6.0 & $+0.4(0.24)^{* *}$ & 5.9 \\
\hline & Codeine/barbiturate combinations (3) & 0.9 & $+0.03(0.07)$ & $\ldots$ \\
\hline & Histamine blockers (3) & 6.8 & $-0.1(0.22)$ & $\ldots$ \\
\hline & Low-efficacy agents with abuse potential (3) $¥ \ddagger$ & 3.5 & $-0.01(0.17)$ & $\ldots$ \\
\hline & Phenylbutazone as a single agent ( 3 ) & 0.2 & $+0.5(0.03) 9$ & 269.6 \\
\hline & Single-agent opiates other than codeine (3) & 1.1 & $+0.04(0.08)$ & $\ldots$ \\
\hline \multirow[t]{4}{*}{ Psychoactive agents } & Antidepressants (2) & 6.0 & $+0.4(0.24)$ & 6.3 \\
\hline & Benzodiazepines (2) & 38.8 & $+3.9(1.30) \#$ & 9.9 \\
\hline & Barbiturates (3) & 7.6 & $+0.7(0.14)$ & 8.6 \\
\hline & Meprobamate with or without aspirin (3) & 0.9 & $+0.1(0.04)^{* *}$ & 9.8 \\
\hline
\end{tabular}

${ }^{*}$ Categories with fewer than 0.5 expected or observed prescriptions per 1000 enrollees per month were eliminated from the table.

$\dagger 1$ indicates likely improvement in therapy; 2 , uncertain effect; and 3 , improvement unlikely.

fEstimated level at start of postintervention period, based on preintervention trend.

$\S$ Estimated change in level of monthly series (prescriptions per 100 patients per month)

Percent change presented only for significant effects $(P<.05)$

$\llbracket P<.0001$.

$\# P<.01$

++ Combinations of aspirin or acetaminophen with pentazocine, propoxyphene, or butalbital.

$\$$ †Pentazocine or propoxyphene alone.

though this was not significantly different from zero ( $90 \%$ confidence interval, $-\$ 115$ to $+\$ 904)$. This was mainly caused by the rise in substitute prescriptions and the higher cost of some of these newer agents. For example, the estimated decrease in monthly costs for study DESI drugs per 1000 enrollees was $\$ 308(\mathrm{SE}=\$ 12)$, while the increase in monthly costs for all defined substitute drugs was $\$ 455(\mathrm{SE}=\$ 130)$.

\section{Predictability of Individual \\ Substitution Effects}

To determine how well specific substitution effects were predicted by the expert panel, we compared predicted use of substitute drugs with actual substitution patterns observed. For each substitute drug, we measured the increase observed in prescribing of the substitute drug divided by the reduction in prescribing of the DESI category to which it applied. This was then compared with the panel's prediction of the likelihood of substitution for each drug. Among the 26 drugs predicted to replace $10 \%$ or more of DESI drug use, 13 actually were substituted at this rate, and the others at a lower rate. Among the 22 drugs predicted to replace less than $10 \%$ of DESI use, 19 were indeed substituted at this rate, with the remaining 3 drugs substituted at a higher rate.

\section{COMMENT}

The impact of various types of formulary restrictions on the prescribing behavior of physicians has been a subject of continuing controversy. Few objective data have been reported, particularly in the office-practice setting, where most prescribing occurs. The results presented previously support the hypothesis that such strategies used alone do not necessarily reduce overall drug use or costs. In fact, our data indicate widespread increases in the use of replacement therapies that, in the aggregate, approximately equalled the costs saved through the reduction in use of DESI drugs. There is substantial evidence for physician use of both desirable and unimproved substitute therapies following the reimbursement changes.
Examples of unlikely improvements in therapy included the substitution of papaverine and ergoloid mesylates for peripheral vasodilators or the substitution of pentazocine- or propoxyphene-containing agents for withdrawn analgesic combinations. On the other hand, the prescriptions of single-agent bronchodilators in place of combinations of these drugs with sedatives represents a probable improvement in the quality of care, assuming that no other negative changes in the dosing of these agents occurred. The observation that sedative prescribing did not increase substantially among patients with asthma who were previously using these combinations suggests either that physicians did not feel that the psychoactive component was needed or that they had not been aware of it. Some substitutions, such as the use of benzodiazepines in place of antispasmodic combinations, were difficult to evaluate without more specific diagnostic information; these effects were thus rated as uncertain changes in the quality of prescribing.

Because of the quasi-experimental nature of this study, it is essential to 
consider alternative explanations for the effects observed. Unlike previous single-observation, before-after studies $^{32}$ that did not control for preintervention trends, we considered only sudden discontinuities in the levels of the series as strong evidence of substitution effects since modest changes in prescribing trends could be caused by many other historical factors, including promotional campaigns and changing knowledge. The large number of significant increases in the level of use of anticipated substitute drugs, all beginning within 2 months following the reimbursement cutoff, and the lack of effect observed for unrelated drug categories (eg, insulin, digoxin) at the same point in the 42-month series reinforces the validity of the causal inferences. Furthermore, the extremely stable characteristics of the Medicaid population, and the fact that the cohorts of long-term users did not include new patients, make it highly unlikely that the effects observed were caused by contemporaneous changes in the population of patients.

Regression artifacts were minimized by requiring that long-term users receive DESI products fairly consistently (one prescription per 4-month period) for 16 months before the intervention. No other drug reimbursement changes occurred in New Jersey Medicaid during the observation period. Finally, it is unlikely that the findings could be explained by multiple significance tests. Approximately half of all substitute drugs showed significant increases; many of these effects were significant beyond the $P<.0001$ level.

As in most other investigations of this type, this study raises as many questions as it was designed to answer. For example, while some out-of-pocket purchases of DESI drugs were possible, ${ }^{14}$ especially for inexpensive or short-term therapies, the precise level of these undesirable effects remains unknown. However, in a program such as Medicaid, serving very poor patients, many physicians would be likely to select another reimbursable drug from the approved list, rather than count on the patient to pay out-of-pocket for an unreimbursed drug. ${ }^{33}$ The extent to which certain patients may have increased their use of other nondrug health services following the withdrawal of medications with perceived effectiveness, especially combination drugs that contained sedatives, is an interesting topic for further research. In general, since the withdrawn agents were judged by experts to lack evidence justifying their continued marketing, we focused on prescribing rather than patient out- comes. Nonetheless, further study of patient compliance and use of other health services following changes in their regimens is warranted. Previous reports of the effects of formulary restrictions on such outcomes are uninterpretable because of methodological inadequacies. ${ }^{3,35}$

It has been noted that most adverse drug reactions are "predictable and preventable through logical application of existing information." ${ }^{36}$ The same may be said of the unintended effects of policy interventions. In several meetings held before the data were analyzed, a small group of physicians and pharmacists were able to predict many substitution effects. The public policy implication of this finding is that it would be quite possible to interview office-based prescribers to learn how physicians are likely to react to planned regulatory interventions. With advance knowledge of potential unintended substitutions, proposed regulations could be modified and educational programs developed to help direct alternative practices in an optimal direction. Failure to consider these predictable substitute behaviors is a common blind spot of many regulatory programs.

This study also makes clear the need to learn more about why physicians choose "nonscientific" treatments in the first place and to develop more effective and appropriately targeted quality assurance policies. If patient or family demands and placebo effects are important factors that drive prescribing, it may be possible to develop office-management policies and educational materials to help physicians reduce the use of certain treatments when they are truly not needed. ${ }^{37.39}$ If lack of knowledge of appropriate treatment choices is the main issue, physicians may simply need objective advice from credible educational sources to improve their prescribing. We have previously shown that face-to-face educational visits by specially trained "academic detailers" could reduce physician prescribing of three targeted drug groups without adverse substitution effects. ${ }^{19}$ Clinically appropriate substitution effects were observed, and the overall benefit-cost ratio was high, even without considering improved quality and safety of care. ${ }^{21}$ Simple restriction policies are more susceptible to inappropriate substitution effects because they usually do not address physicians' and patients' perceived needs for the drug. A promising avenue for further research is to combine such restriction policies with educational outreach programs to encourage use of appropriate replacement therapies.
The applicability of these results to programs of hospital formulary restrictions is less clear. In these settings, where physicians and pharmacists are involved in pharmacy and therapeutics committees, and where programs of inservice education and administrative control often accompany restricted drug lists, ${ }^{40}$ potential unintended substitutions may be circumvented..$^{41,42}$

It is possible that these lessons may generalize to other kinds of physician decision making. For example, physicians have been found to "creatively" adjust to restrictions that prevent the ordering of a battery of laboratory tests with a single order by simply ordering all of the same tests individually. ${ }^{6}$ In addition, it has been hypothesized that the banning in some hospitals of singleunit blood transfusions (which often provide minimum benefits relative to risk) may have resulted in their automatic conversion in many cases to $2-\mathrm{U}$ transfusions, circumventing the point of the restriction. ${ }^{43}$

In the international health arena, our results may also be informative for government programs such as those in Great Britain and Germany, which have recently implemented "negative drugs lists," ending public reimbursement of remedies such as treatments for coughs and colds. ${ }^{4}$ It is tempting to generalize these findings to more restrictive regulations as well, such as Australia's Pharmaceutical Benefits Scheme, which excludes particularly costly drugs in addition to ineffective ones from public reimbursement, and the Essential Drug Programs being encouraged by the World Health Organization for developing countries. ${ }^{5}$ While the need to consider physicians' substitution behaviors and motivations for practice are clearly relevant, more definitive data are needed regarding the overall effects of these very different approaches to the costs and quality of care.

The findings presented herein underline both the opportunities and the limits of restricting physicians' prerogatives to prescribe scientifically unsubstantiated therapies. Although cost savings were not achieved by federal payment restrictions for a group of such drugs, the frequent substitution of efficacious therapies probably represented, at the margin, an overall improvement in quality of care. Medications, like many other medical treatments, are not risk free; the elimination of unnecessary drugs, to the extent to which this occurred, probably reduced the risk of iatrogenic illness. Yet even if all ineffective therapies could be eliminated from medical practice, there is ample evidence to suggest that the remaining " $\mathrm{ef}$ - 
fective" therapies would be misused as well ${ }^{9}$ because of misinformation and other factors that cause nonscientific prescribing in the first place. A broader strategy is needed. Physicians-in-training need to be instilled with an appreciation and understanding of the results of randomized clinical trials, and a healthy skepticism of anecdotal "clinical experience" that flies in the face of such find-

\section{References}

1. Lurie N, Ward NB, Shapiro MF, Brook RH Termination from Medi-Cal: does it affect health? $N$ Engl J Med. 1984;311:480-484.

2. Soumerai SB, Avorn J, Ross-Degnan D, Gortmaker S. Payment restrictions for prescription drugs under Medicaid: effects on therapy, cost, and equity. $N$ Engl J Med. 1987;317:550-556.

3. Holahan JF, Cohen JW. Medicaid: The Trade off Between Cost-Containment and Access to Care Washington, DC: The Urban Institute Press; 1986. 4. Smith T. Limited lists of drugs: lessons from abroad. Br Med J. 1985;290:532-534.

5. WHO Expert Committee. The Use of Essential Drugs. Geneva, Switzerland: World Health Organization; 1985.

6. Eisenberg JM. Doctors' Decisions and the Cost of Medical Care. Ann Arbor, Mich: Health Administration Press; 1986:129-131.

7. Cypress BK. Drug Utilization in General and Family Practice by Characteristics of Physicians and Office Visits: National Ambulatory Medical Care Survey, 1980. Hyattsville, Md: National Center for Health Statistics: 1983:87. Advance Data.

8. US Pharmaceutical Industry, 1986-1987: Annual Survey Report. Washington, DC: Pharmaceutical Manufacturers Association; 1988.

9. Soumerai SB, Avorn J. Efficacy and cost-containment in hospital pharmacotherapy: state of the art and future directions. Milbank Mem Fund $Q$. $1984 ; 62: 447-474$

10. Steel K, Gertman PM, Crescenzi C, Anderson $\mathrm{J}$. Iatrogenic illness on a general medical service at a university hospital. $N$ Engl $J$ Med. 1981;304:63842.

11. Silverman M, Lee PR. Pills, Profits, and Politics. Berkeley: University of California Press: 1974:107-137.

12. National Research Council. Drug Efficacy Study: A Report to the Commissioner of Food and Drugs. Washington, DC: National Technical Information Service; 1969 .

13. Hecht A. A long reach back to assure drug quality. FDA Consumer. 1984;18:15.

14. Smith DM, McKercher PL. The elimination of selected drug products from the Michigan Medicaid formulary: a case study. Hosp Formulary. 1984;19. $366-372$

15. Smith MC, Maclayton DW. The effect of clos- ings. Once in practice, there is a continuing need for accessible, objective, and up-to-date information regarding rational therapeutic decision making. Public policy that builds on such systematic, ongoing education is far likelier to achieve its goals.

This work was supported by grant HS 05554 from the National Center for Health Services Research, Rockville, Md.

ing a Medicaid formulary on the prescription of analgesic drugs. Hosp Formulary. 1977;12:36-41. 16. Ferrando $C$, Henman MC, Corrigan OL. Impact of a nationwide limited prescribing list: preliminary findings. Drug Intell Clin Pharm. 1987;21: 653-658.

17. Cook TD, Campbell DT. Quasi-Experimentation: Design and Analysis Issues for Field Settings. Boston, Mass: Houghton Mifflin Co; 1979

18. Federspiel CF, Ray WA, Schaffner W. Medicaid records as a valid data source: the Tennessee experience. Med Care. 1976;14:166-172.

19. Avorn J, Soumerai SB. Improving drug-therapy decisions through educational outreach: a randomized controlled trial of academically-based 'detailing.' N Engl J Med. 1983;308:1457-1463.

20. Schaffner W, Ray WA, Federspiel CF, Miller WO. Improving antibiotic prescribing in office practice: a controlled trial of three educational methods. JAMA. 1983;250:1728-1732.

21. Soumerai SB, Avorn J. Economic and policy analysis of university-based drug 'detailing.' Med Care 1986;24:313-331.

22. National Technical Information Service Medicaid Data as a Source for Postmarketing Surveillance Information, Vol. I: Technical Report. Research Triangle Park, NC: Research Triangle Institute; 1984

23. Ray WA, Griffin MR, Schaffner W, Baugh DK, Melton LJ III. Psychotropic drug use and the risk of hip fracture. N Engl J Med. 1987;316:363-369.

24. Drug Evaluations. 6th ed. Chicago, Ill: American Medical Association; 1986.

25. American Hospital Formulary Service. Drug Information 86. Bethesda, Md: American Society of Hospital Pharmacists; 1986.

26. Drug Facts \& Comparisons. St Louis, Mo: JB Lippincott; 1983.

27. Ainley W, ed. Martindale, William The Extra pharmacopeia: Incorporating Squires Companion. 27th ed. London, England: Pharmaceutica Press; 1977.

28. SAS User's Guide: Statistics. 1982 ed. Cary NC: SAS Institute; 1982

29. Rao P, Miller RL, eds. Applied Econometrics Belmont, Calif: Wadsworth Publishing Co; 1971.

30. Gortmaker SL, Clark CJG, Graven SN, Sobo AM, Geronimus A. Reducing infant mortality in
We gratefully acknowledge the statistical and data processing support of Dan Gilden, MS, and Seth Racusen, MS; the coding, analysis, and graphic presentation of the data by Elin Griesbach and Sharon Hawley; and the excellent clinical advice of Mark Beers, MD, Dan Everitt, MD, Jerry Gurwitz, MD, and John Foley, PharmD. We are also indebted to the officers and staff of the New Jersey Medicaid program who supplied the data and to Susanne Bellavance and Barbara Arsenault for their assistance in the preparation of the manuscript.

mural America: evaluation of the Rural Infant Care Program. Health Serv Res 1987:22:91-115.

31. Gillings D, Makuc D, Siegel E. Analysis of interrupted time series mortality trends: an example to evaluate regionalized perinatal care. $A m$. Public Health. 1981;71:38-48.

32. Jang R. Medicaid formularies: a critical review of the literature. J Pharmaceutical Marketing \& Management. 1988;2:39-61.

33. Lohr KN, Brook RH, Kamberg CJ, et al. Use of medical care in the RAND Health Insurance Experiment: Diagnosis- and service-specific analyses in a randomized controlled trial. Med Care. 1986;24(suppl):S1-S87.

34. Hefner DL Cost-effectiveness of a Restrictive Drug Formulary: Louisiana vs Texas. Washington, DC: National Pharmaceutical Council; 1980.

35. Hammel RW. Insights into public assistance medical care expenditures. JAMA. 1972;219:1740 1744.

36. Melmon KL. Preventable drug reactions: causes and cures. $N$ Engl J Med. 1971;284:13611368.

37. Spiro HM Doctors, Patients and Placebos New Haven, Conn: Yale University Press; 1986. 38. Schwartz RK, Soumerai SB, Avorn J. Physician motivations for nonscientific drug prescribing. Soc Sci Med. 1989;28:577-582.

39. Marsh GN. 'Curing' minor illness in general practice. $B r$ Med J. 1977;2:1267-1269.

40. Woodward RS, Medoff G, Smith MD, Gray JL III. Antibiotic cost savings from formulary restrictions and physician monitoring in a medical-school-affiliated hospital. Am J Med. 1987;83:817-823. 41. Avorn J, Soumerai SB, Taylor W, Wessels MR, Janousek J, Weiner M. Reduction of incorrect antibiotic dosing through a structured educational order form. Arch Intern Med. 1988;148:1720-1724. 42. Buchwald D, Soumerai SB, Vandevanter N, Wessels MR, Avorn J. Implementation of a hospital-wide reduction in clindamycin dosage scheduled: effects on clinical outcomes. Rev Infect Dis 1989;11:619-624.

43. Tartter PI, Barron DM. Unnecessary blood transfusion in elective colorectal cancer surgery. Transfusion. 1985;25:113-115. 